\title{
Research on the Online Interactive Mode of "One Village, One University Student" Program Course: From an OBE Perspective
}

\author{
Weidi Tan \\ Xiaoshan College, Zhejiang Open University, Hangzhou, Zhejiang \\ Email: 18292340@qq.com
}

How to cite this paper: Tan, W.D. (2021) Research on the Online Interactive Mode of "One Village, One University Student" Program Course: From an OBE Perspective. Open Access Library Journal, 8: e7839. https://doi.org/10.4236/oalib.1107839

\section{Received: August 6, 2021}

Accepted: September 12, 2021

Published: September 15, 2021

Copyright $\odot 2021$ by author(s) and Open Access Library Inc.

This work is licensed under the Creative Commons Attribution International License (CC BY 4.0).

http://creativecommons.org/licenses/by/4.0/

\begin{abstract}
Since its inception in 2004, the "One Village, One University Student" (hereinafter referred to as the OVOUS program), an educational program led by the Ministry of Education of China, has cultivated a large number of talents who have excellent management skills, which effectively promoted the economy in rural areas. Under the rural revitalization strategy, the ever-changing infrastructure construction in rural areas has also led to the development of rural modernized industries; and the development of these modernized industries is bound to put higher requirements on the quality of rural practitioners. The OVOUS program is deeply embedded and serves the rural grassroots. It should also keep pace with the times and continue to develop and innovate in the educational model. During the survey, we found that a large number of rural students have a strong demand for upgrading the original online courses, and the mechanical one-way teaching output can no longer meet their learning needs; and since the COVID-19 epidemic, many practical courses in the OVOUS program have encountered a big bottleneck in the implementation of teaching and interactions. And the teaching effect has been greatly affected, especially under the actual conditions of online interaction of the whole course, the quality of online interaction is not ideal. To inspire those students from rural areas to have stronger motivations in participating in the OVOUS program especially during post-epidemic era is the starting point of our research; and the purpose of our research is to discover the way to enable these students to learn better and achieve better performances through those effective online interactions.
\end{abstract}

\section{Subject Areas}

E-Learning and Knowledge Management 


\section{Keywords}

OBE, “One Village, One University Student”, Online Interactive Mode, Innovation Research

\section{Introduction}

\subsection{Research Background}

"One Village, One University Student" (hereinafter referred to as "the OVOUS program") is an educational program led by the Ministry of Education and organized and implemented by the Open University of China, which aims to cultivate various professional, skilled and managerial talents to meet the needs of rural economic and social development. In the autumn of 2004, the OVOUS program began, combining face-to-face teaching with online teaching, and offering a total of 18 related majors such as agriculture, forestry, animal husbandry and management. Later, the project was extended to the whole country. By the end of 2018, 1,513 learning centers in 42 provincial-level radio and television universities (branches of the Open University of China) and the Open University of China School of Experiment had participated in the implementation of the project, offering 25 related majors in seven disciplines, with a total enrollment of 687,579 students and 459,536 graduates. For China's new rural construction has trained a large number of stay, use, understand science, skills, can manage the farmers to start up and get rich leaders and political quality, management ability of rural grassroots cadres, in the regional economic development, consolidate the rural grass-roots organizations, promote the village civilization and other aspects played a positive role [1]. The OVOUS program is a new measure to develop rural higher education. It is an important exploration of Open University of China to provide higher education services for farmers and promote educational equity. It is also an important starting point for Open University of China to serve the society, especially to serve the construction of new socialist countryside. In September 2018, the CPC Central Committee and The State Council issued the Rural Revitalization Strategic Plan (2018-2022). "Cultivate a new generation of professional farmers who love agriculture, know technology and are good at management, and optimize the structure of agricultural practitioners." the report said. We will implement a program to cultivate new types of professional farmers and support them in participating in secondary and higher agricultural vocational education through flexible schooling systems. "We will innovate the form of training organizations and explore training methods such as field classrooms and online classrooms". At the Central Conference on Rural Work in December 2020, General Secretary Xi Jinping proposed to "mobilize the entire Party and society to promote rural revitalization, promote high-quality and efficient agriculture, make rural areas livable and productive, and make farmers rich and prosperous". All of these provide fundamental adherence and 
strong guarantee for the implementation of the OVOUS program curriculum. In the new period, for further promoting rural revitalization strategy, the OVOUS program need to absorb the reference project leading experience, through increasing their support, strengthen the top-level design, focus on the balanced development, strengthening personnel training pertinence, extension of social participation in such aspects as promoting sustained and healthy development, project for better rural revitalization of the local talent cultivation, and provide personnel support strengthening rural revitalization [2].

\subsection{Research Review}

\subsubsection{Connotation and Research Status of OBE Educational Concept}

OBE originated from the basic education reform movement in North America in the 1980s. As an educational power, The United States began to reflect on the practicality of education and the importance of results because it was not satisfied with its own contributions and performance in science and technology. In this context, OBE was first proposed by Spady in 1981. It pays attention to the actual needs of the society for talents, emphasizes the rational arrangement of teaching time and the design of key teaching resources around the learning output. There are many researches on OBE model in domestic and foreign literature, and the researches are mainly carried out from three levels: macro, meso and micro [3].

\section{1) Macro level}

Research are mainly distributed in OBE theory research literature review, the whole course system construction of colleges and universities under the theory of OBE, OBE theory under the guidance of the personnel training mode of study, comparative study of OBE's theory in the western colleges and universities and some cold thinking of OBE theory, and the evaluation of the effectiveness. The basic principle of the OBE philosophy is: Success for All learners. The logical architecture of the idea is that every student is talented, that learning should be based on collaboration rather than competition, and that schools should be educational institutions that find ways for each student to succeed. Based on the logic of this educational concept, Spadi, the proposer of OBE, proposed the pyramid structure of results-oriented education in 1994. The structure divides outcomes-oriented education into five areas: an implementation paradigm, two key objectives, three key premises, four implementation principles and five implementation points. "An implementation paradigm" means that the implementation of OBE should begin with a clear vision and framework. This vision and framework should clearly clarify students' abilities in the professional field, and design the framework system of teaching objectives, course organization, teacher teaching and teaching evaluation around the specific abilities. The "two key goals" refer to building a blueprint for outcomes and creating situations and opportunities for success. The blueprint should indicate the knowledge, ability and value pursuit that students should have upon graduation, and 
the creation of successful situations and opportunities is a sufficient condition for the realization of the blueprint. "The three key premises" mean that "all students can learn and succeed", "the work of the school will directly affect students' learning" and "successful learning leads to more successful learning". In the OBE concept, "four principles of implementation" have been inherited and practiced by scholars of various countries. The four principles boil down to: first, focus clearly, focus is important peak results; second, downward design, from the final, peak results to create downward; third, high expectations for all students to succeed; fourth, expand opportunities and enhance the opportunities for successful learning. Jobs Brandt further explained the above four principles from the perspective of instructional design. He believes that the peak outcome of clear focus should be for students to demonstrate the ability to apply what they learn in a comprehensive way at the end of the learning process, rather than the week, semester or year itself. The downward design takes peak performance as the ultimate goal, and the curriculum and instructional design return to the ability that students can carry with them. High expectations mean that teachers should view the student's learning process as a high-level challenge to self-actualization, and instead of setting general standards for students, they should expect them to achieve self-actualization. Expanding opportunities requires teachers to respond in a more flexible way to the individual needs of students and to create opportunities for students to practice what they have learned to demonstrate the effectiveness and usefulness of their learning. The "five implementation points" include five aspects: clarifying learning outcomes, constructing curriculum system, clarifying teaching strategies, forming self-referential evaluation and reaching the top step by step [4].

\section{2) Meso level}

The research focuses on curriculum design under the guidance of OBE theory, including overall curriculum design, curriculum objective design, learning outcome design, curriculum training design and so on. In order for the OBE theory to be well implemented, the following three conditions need to be met: first, it is necessary to recognize that all students can succeed in learning, but there are some differences in the time and method of success. Second, after students experience successful learning, they will form psychological advantages, which will motivate them to achieve greater success. Third, teachers play a crucial role in the implementation process, which determines whether students can achieve success to some extent. In addition, the implementation of OBE theory also needs to adhere to the following basic principles: first, pay attention to the results with obvious significance; second, to provide students with the necessary support for success; third, believe that students will succeed; the fourth is to reverse design the teaching according to the expected results [5].

\section{3) Micro level}

The research mainly focuses on curriculum practice under the guidance of OBE theory, such as teaching mode reform research, classroom teaching method 
reform and comparative research, curriculum resource construction research, curriculum monitoring and evaluation research and so on. At the application level, there are three types of OBE: traditional OBE that emphasizes professional skills and their structural manifestations; transitional OBE emphasizing unstructured performance and high-level capabilities; focus on life role competencies and transformational OBE determined by complex role performance. Traditional OBE learning outcomes can be divided into two levels: professional skills and structural performance. At the level of professional skills, teachers make professional course content in advance and evaluate the learning results according to the professional scores. The structural performance is reflected in the specific projects, modules and steps that students carry out to achieve professional skills. In contrast to the former type, transformational OBE emphasizes that the purpose of the school is to develop students with the knowledge, abilities and characteristics that are appropriate for future citizenship orientation. However, the school teaching concept based on the contemporary curriculum structure and teaching mode cannot produce students who can succeed in the complex and challenging high-tech living environment of the future. Therefore, the core concept of transformational OBE lies in the orientation of future-oriented learning outcomes. Transitional OBE is somewhere in between, emphasizing higher-level competencies and learning outcomes with unstructured performance. Here, high-level competence refers to the ability to solve practical problems by using critical thinking and integrating learned knowledge, not limited to specific subject knowledge. Unstructured performance refers to performance in more complex tasks that require integrating knowledge from different perspectives or designing one's own learning program and determining its scope, implementation criteria, and measurement methods. In practice, although traditional OBE is widely adopted in the United States, Canada and other countries, it is undeniable that it is an internal and narrow learning outcome. It is embodied in the following aspects: first, the course content and learning results are usually classified according to the traditional subject content, which is disconnected from the real life experience; second, the concept of students' best learning performance is limited to individual courses or a small part of teaching activities, learning is regarded as separate activities; third, the core points to the academic ability of graduates, rather than whole-person development; fourth, its structure is a single classroom teaching, not with the real life role and environment context. Although transformational OBE has some advanced educational concepts, it is undeniable that the core orientation of "future learning outcomes" is characterized by complexity and difficulty in practical operation. In addition, the fact that China is a big educational country rather than a strong educational country also has a certain influence on the specific functions of this concept in practice. The transitional OBE not only overcomes the disadvantages of the traditional OBE, but also can be based on the actual education in China. At the present stage, this idea should be adopted to reconstruct China's educational thought, 
teaching idea and teaching design [6].

\subsubsection{Practical Research on the OVOUS Program Course}

At present, the academic research on this issue mainly starts with the analysis of students, the characteristics of courses and resources, and the status quo of teaching mode. The main research results are summarized and sorted out as follows:

\section{1) Analysis of trainees}

Research points out, the OVOUS program course students mostly from the countryside, there are whole older, cultural foundation weak, the contradiction in engineering, accustomed to the traditional face-to-face teaching, remote autonomous learning ability is limited, such as the reality, most of them engaged in side-line and fishery, and other various industries, everyday is busy with work, scattered space distance, learning time is limited, Learning concept and learning means are relatively backward, learning environment and learning conditions are relatively poor. At the same time, due to the fact that most of the course students study part-time, there are many interference factors, and the time of independent learning cannot be guaranteed, so the learning incidence is low. It is understood that the majority of students live far away from the learning center, it is not convenient to attend the face-to-face tutoring, and the attendance rate of the face-to-face tutoring and answering classes organized by the learning center is low.

\section{2) Analysis of characteristics of courses and resources}

As a distance higher education, teaching media resources are the main media for communication between teachers and students. Therefore, in the integrated design and construction of multiple media, the Open University of China fully takes into account the economic affordability of low-income students in rural areas, and specially develops the low-cost the OVOUS program course for students. Convenient and practical multimedia teaching resources, such as "rural edition" multi-media teaching materials and study packages, are about 30\% cheaper than other similar teaching products, making it possible for low-income people to go to university. At the same time, we make full use of the distance education network of the OVOUS program, the distance education network of China Education channel and other media means to transmit teaching resources and teaching information. Also according to the local provincial TV university student to study the characteristics and actual demand, timely supplementary teaching resources, to serve the needs of teaching, so that "takes a" relatively rich course content and resources is more, but the lack of consistency to guide teachers, it is difficult to timely in the course of rendering, so it is hard to guarantee a gap and the teaching effect [7].

\section{3) Analysis of current teaching mode}

The courses of the OVOUS program are mainly taught online, and the online courses are mainly one-way output by teachers. There is a lack of communication and interaction with students, and they cannot receive feedback on teaching 
results in time. At the same time, the teaching mode is also faced with the impact of uncertainty caused by major public emergencies. When the COVID-19 hit, all students were suspended, and online teaching played an important role. However, as the epidemic prevention and control situation becomes normal, more effective measures should be taken to put an end to improvisation-style online teaching and gradually normalize online teaching interaction to prevent learning for learning's sake, going through the process and coping learning.

\subsubsection{Comparative Study of Teaching Interaction Modes}

At present, the comparative study of traditional teaching interaction mode and online teaching interaction mode under COVID-19 mainly starts from the three levels of teachers, students and teaching elements, which can be summarized as follows:

\section{1) Traditional teaching interaction mode}

From the perspective of teachers, traditional education is face-to-face teaching and learning between teachers and students at school. It centers on teachers and classroom. The teaching method is relatively simple, but teachers can intuitively observe students' learning status and interact with students in the first time. From the perspective of students, the biggest advantage of traditional teaching is that teachers and students can communicate face to face, which can ensure the on-site teaching atmosphere and the sense of class ceremony. This is also the reason that most students have special feelings for traditional teaching. From the level of teaching elements, the timely classroom teacher-student interaction and the real-time communication between students have more teaching elements, which is one of the advantages of traditional teaching. Although online education can also solve the problem of interaction, it is still not intuitive and the effect is not outstanding. But the traditional teaching mode fixed place, fixed time, single teaching method and so on is the traditional teaching big problem, especially for some class time emergencies and can not come to the classroom teachers and students, traditional teaching to some extent can not meet the class time and site flexible arrangement.

\section{2) Interactive mode of online teaching under COVID-19}

From the perspective of teachers, the interactive online teaching mode under the COVID-19 pandemic has no restrictions on teaching places. Teachers can flexibly arrange their learning time and place according to their needs, which has greater autonomy and convenience, saves a lot of commuting time and avoids the risk of epidemic transmission caused by people gathering. At the student level, learners can use online tools to participate in learning anytime and anywhere, and ask teachers questions and discuss problems with classmates. The teaching methods are more diversified. From the point of view of the level of teaching elements, online teaching is not only a new education method of the development of The Times, but also can provide convenience for students, but also can reduce the cost of teaching, can cross the limitations of space and location through high-speed data, greatly enrich the educational resources, the ad- 
vantages are obvious. However, the disadvantages are also obvious. For example, some teaching elements are deficient, interactive experience will be weakened, there is no communication between people, and the temptation of electronic products without supervision is great. Students do not pay attention to lectures, skip classes and default on homework are common. Of course, many online education platforms are working to improve the problem, and there are many ways to monitor it. For example, other entertainment platforms cannot be opened during the learning process, and there will be classroom questions from time to time to catch students' attention. The current problem of online teaching is that it is restricted by the Internet speed. Students with fast Internet speed have smooth pictures and can interact with teachers in real time to complete the teaching task better. The students with slow Internet speed can not synchronize their pictures, which seriously affects the quality of teaching. If the teacher-end Internet speed is slow, the consequences are more serious, and over time it is likely to bring about the overall teaching progress lag.

\subsection{Research Summary}

Although the current research has made many achievements, there are still some shortcomings, such as the research perspective is not unique enough, and some scientific theories, such as OBE theory, have not been organically combined with the curriculum practice research. The scope is not wide enough, and it is mostly confined to some specific places and individual regions. For some emergencies, such as the COVID-19 outbreak, the research on how to enrich the teaching path and improve the learning effect is not sufficient, and the research on the quality of online interactive teaching is not deep enough, which needs to be further improved and strengthened in future research.

\section{Problems Faced by the Online Interactive Mode of the OVOUS Program Course}

Measured from the perspective of OBE, in the specific practice of online teaching of the OVOUS program course, some problems need to be solved:

\subsection{Some M00Cs Serve as Content Management Systems Rather than a Good Learning Management System}

Moocs mainly use video as a carrier and have significant interactive functions, which can be sent to the Internet for free, so that students all over the world can learn together. In the course, teachers usually divide the videos into several small videos to spread the corresponding teaching content, and set real-time tests and feedback training questions to promote teachers and students to better participate in learning. The characteristics of MOOCs are reflected in famous teachers and immediate feedback, which mainly play to the advantages of big data and promote the transformation of teaching. The downside of MOOCs, however, is that there is no uniform video for all students, and they do not cater to all sub- 
jects at once. Therefore, as a content management system, MOOCs can solve problems to a certain extent and provide more opportunities for education and teaching reform, but it is not a good learning management system and cannot play the role of managing and improving the learning effect of students.

\subsection{Lack of Learning Motivation Caused by Single Learners' Separation from Physical Classrooms}

Since the outbreak of the COVID-19 outbreak, home-based distance learning and online learning have become the new normal. However, the problems exposed are also very much. For example, people's communication and social needs are not well met; the lack of ritual, loneliness, and the absence of a conformist atmosphere in a group environment in online learning make many online learners, including adult learners, feel distressed and unable to focus on learning. At the same time, due to the lack of effective supervision means, online learning results are difficult to be guaranteed.

\subsection{Interactive Unidirectional Problems in Traditional Distance Teaching Mode}

In recent years, the online course model in schools at home and abroad to break the regional and temporal constraints of education, providing students with convenient, targeted education guidance services, gradually accepted and welcomed by the majority of teachers and students. However, there is a unidirectional interaction problem, interaction interaction experience is poor. Many students believe that video learning on the current distance learning model is a monotonous, single-person way of learning. After teachers upload online courses, they will no longer appear in time. In this way, in the comment area and message area, many students constantly ask teachers questions about the courses, but it is difficult for teachers to answer them in real time. This monotonous and lack of interactive online course experience has greatly discouraged the learning enthusiasm of students in continuing education in colleges and universities. In the long run, students do not have a sense of belonging, will slowly away from this teaching mode. In addition, due to the lack of channels for students to communicate and communicate with teachers, for many students, watching teaching videos is greatly less interesting and situational experience. Without the encouragement of teachers and the cooperation of classmates, it is difficult for a person to persist in learning all the relevant courses. Therefore, poor interactivity is one of the key factors why traditional classroom teaching experience is obviously better than online classroom experience in many cases [8].

\section{Countermeasures and Suggestions to Improve the Online Interaction Quality of the OVOUS Program Course}

Combined with OBE results-oriented theory, it is suggested that in the implementation of the OVOUS program course, the needs of farmers as a specific 
group should be combined, the advantages of online teaching should be fully played, and the online interactive teaching mode should be improved from the following aspects to enrich the experience of running courses.

\subsection{Build a Multi-Linkage Organizational Management System}

It is suggested to draw lessons from successful experiences at home and abroad, build a multi-body linkage pattern of "two vertical and one horizontal", and strive to promote the organization, management, implementation and promotion of online teaching of the OVOUS program course. "One vertical" refers to the organic linkage between the central education administrative department-the relevant provincial administrative departments-the relevant prefecture-level administrative departments-the relevant county and township administrative departments, to promote governments at all levels to formulate relevant policies from top to bottom, mobilize funds and forces, and effectively implement the organization, support and management of the OVOUS program. "Two longitudinal" refers to the headquarters of the national Open University-division-school-learning center system linkage, in project design, organization, operation, major setting and course setting, learning resources construction, and other aspects of teaching and teacher training unified understanding, overall coordination, sharing large system complete network education teaching resources, realizing the sharing of information exchange, The multi-level educational organization system should be subdivided into the rural society to ensure the wide coverage of distance higher education to the dispersed and large number of farmers. "One horizontal" mainly refers to the effective communication and coordination between local open universities and local governments, linking the OVOUS program course with local rural grassroots organization construction, targeted poverty alleviation, cultivation of new professional farmers, various skills training, cultural construction and other projects. The coordination mechanism among universities, functional departments, enterprises, scientific research institutions and other social forces should be established under the promotion of the government. Social resources should be explored and integrated through resource sharing, so as to consolidate the foundation of talent training and ensure that the quality of talent training meets the needs of regional economic and social development.

\subsection{Innovating Distance Education Teaching Mode}

It is suggested to give full play to the synergistic effect of diversified teaching methods and promote the integration of traditional teaching and information teaching according to the reality of rural college students. First, make full use of modern information technology to support students' independent study. We should give full play to the advantages of multimedia technology and network interaction, carry out online teaching, pilot mobile learning, set up micro courses, and use social media such as Weibo, QQ, Dingtalk, Zoom and WeChat to create 
multiple teaching environments to support students' ubiquitous learning, collaborative learning, mutual help and mutual teaching, so as to improve their independent learning ability. Second, face-to-face teaching should be increased. In addition to the regular face-to-face teaching, we should increase the face-to-face teaching period according to the farming time, organize teachers' groups to give concentrated face-to-face teaching in the slack farming season, and "send teachers to the countryside" and "send teachers to the home" in the busy farming season. Third, use local materials to carry out practical teaching. This kind of "field class" with zero distance contact with entrepreneurs not only helps farmers to deepen their understanding of theoretical knowledge, but also helps to apply what they have learned to practice, train students' technical skills, and inspire and induce innovation and entrepreneurship [9].

\subsection{Improve the Talent Training Mode}

Suggestions combined with the target of the OVOUS program course, in the implementation of the OVOUS program course fully meet the needs of regional economic and social development, exert the characteristic resource condition, in the reform of the school system and mechanism, expand training content, promote the reform of education teaching mode active exploration, innovation, accumulated rich experience, formed distinctive model of talent cultivation. The first is to adopt multi-subject cooperation in running schools and mobilize multiple resources for joint promotion. The main performance is school-toschool cooperation and school cooperation. The second is to adjust the goal and mode of personnel training by connecting the needs of regional economic and social development. For example, docking with the "Quality Improvement Project of Rural Party Members and Cadres", carrying out higher educational background education of rural party members and cadres, training rural grassroots organization cadres and reserve talents; to meet the development needs of regional characteristic industries and train technical and technical talents [10].

\subsection{Strengthen Resource Construction, Integration and Sharing}

It is suggested to strengthen resource construction and integrate and share social resources to provide support for the operation of the OVOUS program according to the characteristic demand of farmer college students for educational resources. First, strengthen the construction of network learning platform. Relying on the national Open University learning network, "the project of one undergraduate in one village", distance education, the university student village official learning network, integration of local network resources, structures, including air class actively, Weibo, QQ, WeChat network interactive learning platform, reduce time and space limit, to get the students to learn, communication, learning resources and a variety of services to provide a full range of support. Second, strengthen the construction, integration and sharing of curriculum resources to 
meet the "fragmented" learning needs of students. Third, gather social forces to enrich teachers' resources. By means of school-school cooperation, school-local cooperation and school-enterprise cooperation, professors, experts, technicians, entrepreneurs and professionals in functional departments are invited as part-time teachers to provide students with diversified teaching services. Fully excavate and mobilize the village society in the village talents, talented people, retired old teachers, senior cadres, village officials and other college students to establish a volunteer team, in the auxiliary learning, skills training and other aspects of the growth of rural college students.

\subsection{Establish Financial Guarantee and Incentive Mechanism}

It is suggested that we should be results-oriented, earnestly implement the guidelines of the Ministry of Education, actively explore the ways of raising funds through multiple channels in the process of implementing the OVOUS program, and establish a financial guarantee system for peasant college students that combines profit from schools, government support and individual self-support. At the same time, we will actively explore the establishment of relevant supporting systems to encourage rural college students to pursue their studies locally and take root in their hometown. First, we can try to give preferential policies to rural college students for innovation and entrepreneurship, poverty alleviation and prosperity, especially in the aspects of project operation, financial discount loans, tax reduction and exemption. Second, we should pay attention to the follow-up training and application, and create upward channels and development space for talents.

\section{Summary and Outlook}

To sum up, from the perspective of OBE, the innovative research on the OVOUS program course through distance online education is an important part of cultivating local talents for rural revitalization, as well as an important part of China's "agriculture, rural areas and farmers" work and farmer education. Implement the strategy of rejuvenating the country and in the current countries in urgent need of strengthening talents under the background of support, the OVOUS program training farmers experience, students' achievements, will for the new period to explore a new method of constructing rural human capital development, the new mechanism, cultivate more to retain, use, well done, take up "permanent" brand the country revitalization of the talent team to provide the beneficial reference and reference. It is believed that with the joint efforts of all parties, the future the OVOUS program project will be more and more popular and more effective.

\section{Fund Project}

This article is a general research subject of the Zhejiang Provincial Department of Education (Y201941596), Zhejiang Open University 2020 Higher Education 
Teaching Reform Project (XJG202007) and Zhejiang Open University 2019 "312 Talent Training Project" research results.

\section{Conflicts of Interest}

The author declares no conflicts of interest.

\section{References}

[1] Chen, C.Z. (2018) Gathering Talents to Help Rural Vitalization-Speech at 2018 High-Level Dialogue on Vocational Education and Urban Development (Excerpt). China Vocational and Technical Education, 26, 5-7.

[2] He, Z.G. (2018) Promoting Agricultural and Rural Modernization through the Revitalization of Rural Talents. Guangming Daily, 10-29. http://www.ce.cn/xwzx/gnsz/gdxw/201810/29/t20181029_30655056.shtml

[3] Hu, Y.W. (2017) Providing Strong Talent Support for Promoting Rural Revitalization. Rural Work Newsletter, 27-30.

[4] Li, Z.Y. (2015) Results-Oriented Teaching Design. University Teaching in China, 37, 32-39.

[5] Jiang, C.Y. (2018) Accurately Grasp the Connotation and Essence of Rural Revitalization Strategy and Planning. Dongyue Pancong, 29, 25-33.

[6] Xue, Y. (2018) Study on the Status Quo and Countermeasures of Local College Students' Online Elective Courses. Modern Communication, 32, 7-8.

[7] Hou, L.L. (2017) Investigation and Analysis of Students' Acceptance and Use of Distance Teaching Mode in the "Internet +" Environment. Library World, 38, $8-12+36$.

[8] Yang, Z. (2015) Motivation and Dimension on Development of Peasantry Education in China-Based on the Perspective of Demography. Vocational and Technical Education, 36, 65-69.

[9] Zhang, X.M., Zhong, Z.X. and Shen, J.H. (2016) Study on Teaching Quality Evaluation System of Distance and Open Education for "One College Student in One Village". Distance Education in China, 36, 33-40+80.

[10] Han, Y.Q. (2015) Development of Vocational Education in China: Current Situation, Problems and Strategies. Vocational and Technical Education, 36, 17-22. 